\title{
Infodemic, self-medication and stockpiling: a worrying combination
}

Shoaib Ahmad, ${ }^{1}$ Maryam Salma Babar, ${ }^{2}$ Mohammad Yasir Essar, ${ }^{3,4}$ Mehul Sinha ${ }^{5}$ and Azhar Nadkar ${ }^{6}$

${ }^{1}$ Punjab Medical College, Faisalabad, Pakistan. ${ }^{2}$ Dubai Medical College, Dubai, United Arab Emirates. ${ }^{3}$ Kabul University of Medical Sciences, Kabul Afghanistan; ${ }^{4}$ Medical Research Center, Kateb University, Kabul, Afghanistan ${ }^{5}$ Kasturba Medical College, Mangalore, India. ${ }^{6}$ Stellenbosch University, Cape Town, South Africa. (Correspondence to: Shoaib Ahmad: shoaibahmad442@gmail.com).

Citation: Ahmad S; Babar M; Essar M; Sinha M; Nadkar A. Infodemic, self-medication and stockpiling: a worrying combination. East Mediterr Health J. 2021;27(5):438-440. https://doi.org/10.26719/emhj.21.010

Received: 29/08/20; accepted: 03/02/21

Copyright (C) World Health Organization (WHO) 2021. Open Access. Some rights reserved. This work is available under the CC BY-NC-SA 3.0 IGO license (https://creativecommons.org/licenses/by-nc-sa/3.o/igo)

\section{Introduction}

Self-medication is the practice of selecting and administering drugs to oneself or family without a physician's prescription or consulting a doctor in case of minor illnesses or self-diagnosed conditions (1). Families, friends, neighbours, pharmacists, previous drug prescriptions, opinions formed from advertisements in newspapers, popular magazines and social media are the most common sources of self-medication in low and middle-income countries in the Eastern Mediterranean Region (2-4).This practice more often causes increased tolerance to antibiotics and other subsequent health issues such as pathogen resistance, increased morbidity and inappropriate treatment (5). Some common antibiotic-resistant microorganisms include methicillin-resistant Staphylococcus aureus (MRSA), glycopeptide-resistant S. aureus, and toxin hyperproducing Clostridium difficile. In addition, amoxicillin, macrolides, fluoroquinolones, cephalosporins and metronidazole drugs are the most common antibiotics used for self-medication. For example, irrational usage of amoxicillin may have adverse effects such as medication tolerance and nil response to treatment in acute otitis media, pneumonia, and urinary tract infections where amoxicillin is considered as a firstline antibiotic (6).

\section{Self-medication and COVID-19}

The spread of COVID-19 has galvanized researchers to find an effective treatment as well as developing a vaccine. Hydroxychloroquine, azithromycin, ivermectin, remdesivir, chlorine dioxide and lopinavir are among a number of drugs that appear useful for the treatment of COVID-19 (Table 1). However, randomized clinical trials are required to build an evidence-based treatment for COVID-19 (7). Recently, dexamethasone proved to be a very instrumental addition with the drug proving vital for hospitalized patients on respiratory support (8).

The information available online may pose dangers to public health and the array of possible treatments shared on social media can encourage a greater tendency to self-medicate by the general public. In addition, the misinformation online may have initiated a wave of the virus in the first place as people were not provided with the correct protocols and measures to control its spread (9). Many are sceptical about visiting hospitals for COVID-19 tests; since the public relies on the internet and social media to obtain sensitive information regarding the management of coronavirus, they are very likely to end up with misleading information. Thus, there has been a marked increase in the number of people searching online to self-medicate during this pandemic (10).

For chloroquine in adults, the lethal dose is estimated to be between 30 and $50 \mathrm{mg} / \mathrm{kg}$, while doses higher than $20 \mathrm{mg} / \mathrm{kg}$ can also be toxic (11). These dosages can highly vary in older patients and those having comorbidities, especially cardiac issues. Many observational studies concluded that the usage of hydroxychloroquine, chloroquine and/or azithromycin were associated with QT prolongation and any need for usage must outweigh potential adverse effects (12). The use of these drugs is purely case based and cannot be done without a registered medical practitioner (13). Reports in Nigeria claimed that three people had overdosed on chloroquine after claims on social media about the efficacy of the drug (14). Similarly, ivermectin can result in serious consequences in pregnant women and in patients suffering from meningitis (15). In addition, the use of dexamethasone in

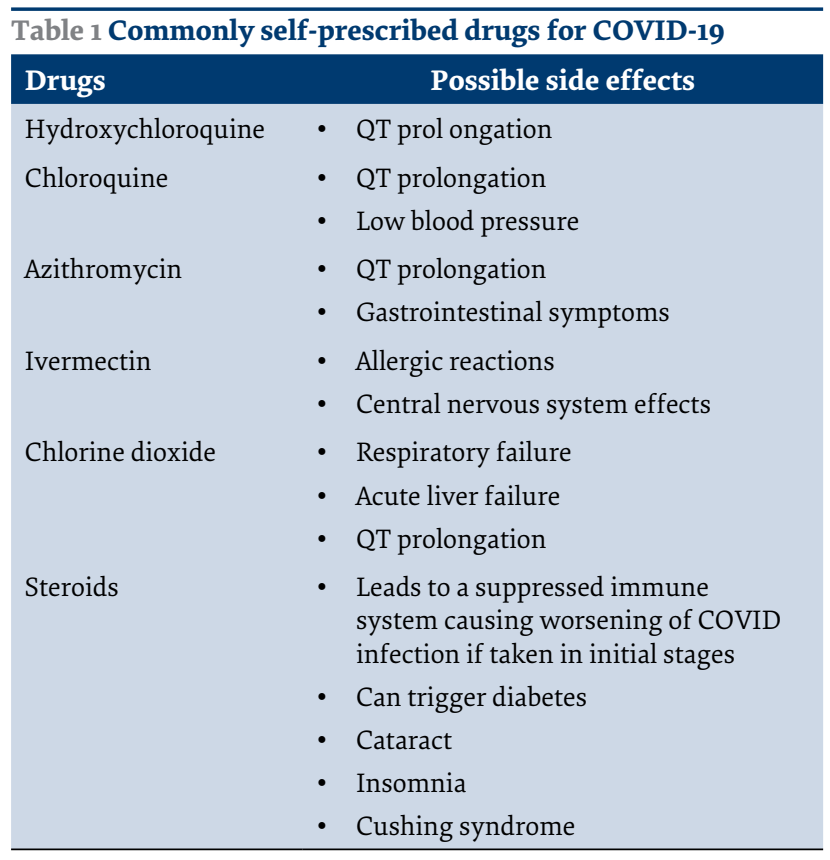


asymptomatic or mildly symptomatic patients can cause deteriorating effects; the drug proved to have no effect on patients without respiratory support and the undue use of steroids is associated with complications (2).

Another area of concern with regard to self-medication is stockpiling, which leads to a shortage of these very necessary drugs in the market. Drugs that are certified for COVID-19 treatment have several proven uses and stockpiling these leaves many people devoid of these essential medications. For instance, chloroquine is used to treat malaria and many autoimmune diseases that include systemic lupus erythematosus and inflammatory arthritis (16). The scarcity of life-saving medications gives rise to increased expenses, patient harm, and increased errors by health workers, causing widespread apprehension in oncology, infectious disease, critical care, and many other settings (17). Hence, stockpiling deprives patients of their necessary medications and limits treatment in the context of this pandemic.

\section{What can be done?}

Strict regulations need to be imposed to prevent stockpiling of essential medicines. Health professionals need to educate the general public; proper health education can significantly affect the views held by people, which in turn can have a positive influence on their family members and friends. Governments should develop strategies to regulate information regarding possible medications on the internet and further research to pinpoint the platforms dissipating misinformation. In addition, there should be improvement in the workflow in pharmacies, strict control regarding pharmaceutical advertisements, and improved communication between pharmacists and clinical teams on how supplies may affect health-care delivery.

\section{Conclusion}

The COVID-19 pandemic has given the practice of self-medication a new impetus that is supported by social media platforms, which actually hinder effective and concise information on ways to prevent and treat COVID-19. The knock-on effect of drug stockpiling needs to be addressed so that medicines can effectively reach the most vulnerable; this requires the implementation of stringent laws and policies by governments to prevent easy availability of over-the-counter drugs. In particular, governments need to add special focus on monitoring and tackling the problem of medical misinformation among the public.

\section{References}

1. Jember E, Feleke A, Debie A, Asrade G. Self-medication practices and associated factors among households at Gondar town, Northwest Ethiopia: a cross-sectional study. BMC Res Notes. 2019; 12(1) Doi: 10.1186/s13104-019-4195-2

2. Yousef AMM, Al-Bakri AG, Bustanji Y, Wazaify M. Self-medication patterns in Amman, Jordan. Pharm World Sci. 2008; Jan;30(1):24-30. doi: 10.1007/s11096-007-9135-X

3. Awad A, Eltayeb I, Matowe L, Thalib L. Self-medication with antibiotics and antimalarials in the community of Khartoum State, Sudan. J Pharm Pharm Sci a Publ Can Soc Pharm Sci Soc Can des Sci Pharm. 2005 Aug;8(2):326-31.

4. Alghanim SA. Self-medication practice among patients in a public health care system. East Mediterr Health J. 2011 May;17(5):409-16.

5. Bennadi D. Self-medication: a current challenge. J basic Clin Pharm. 2013;Dec;5(1):19-23.

6. Nepal G, Bhatta S. Self-medication with antibiotics in WHO Southeast Asian Region: a systematic review. Cureus. 2018 Apr 5;10(4).

7. Pascarella G, Strumia A, Piliego C, Bruno F, Del Buono R, Costa F, et al. COVID-19 diagnosis and management: a comprehensive review. J Intern Med. 2020 Aug;288(2):192-206.

8. Dexamethasone in hospitalized patients with Covid-19 - Preliminary Report. N Engl J Med. 2020 Jul 17;NEJMoa2021436. doi: 10.1056/NEJMoa2021436

9. Cuan-Baltazar JY, Muñoz-Perez MJ, Robledo-Vega C, Pérez-Zepeda MF, Soto-Vega E. Misinformation of COVID-19 on the Internet: infodemiology study. JMIR public Heal Surveill. 2020 Apr;6(2):e18444.

10. Onchonga D. A Google trends study on the interest in self-medication during the 2019 novel coronavirus (COVID-19) disease pandemic. Saudi Pharm J. 2020;28(7):903-4. (http://www.sciencedirect.com/science/article/pii/S1319016420301262).

11. Karalis V, Ismailos G, Karatza E. Chloroquine dosage regimens in patients with COVID-19: Safety risks and optimization using simulations. Saf Sci. 2020 Sep 1;129:104842.

12. Hsia B, Greige N, Quiroz J, Khokhar A, Daily J, Di Biase L, et al. QT prolongation in a diverse, urban population of COVID-19 patients treated with hydroxychloroquine, chloroquine, or azithromycin. J Interv Card Electrophysiol. 2020;1.

13. D'Cruz M. The ICMR bulletin on targeted hydroxychloroquine prophylaxis for Covid-19: Need to interpret with caution. Indian J Med Ethics. 2020;V(2):100-2.

14. Nigeria records chloroquine poisoning after Trump endorses it for coronavirus treatment - CNN (https://edition.cnn. com/2020/03/23/africa/chloroquine-trump-nigeria-intl/index.html). 
15. Chaccour C, Hammann F, Ramón-García S, Rabinovich NR. Ivermectin and COVID-19: Keeping Rigor in Times of Urgency. Am J Trop Med Hyg. 2020 Jun;102(6):1156-7. (https://pubmed.ncbi.nlm.nih.gov/32314704).

16. Al-Bari MAA. Chloroquine analogues in drug discovery: new directions of uses, mechanisms of actions and toxic manifestations from malaria to multifarious diseases. J Antimicrob Chemother. 2015;70(6):1608-21.

17. Fox ER, Unguru Y. Oncology drug shortages in the USA - business as usual. Nature Reviews Clinical Oncology. 01 Mar 2020;17(3):128-129 doi:10.1001/jamapediatrics.2019.0070 